\title{
Taalgebruik in godsdiensuitsendings 1
}

\author{
Hans du Plessis \\ ATKV-skryfskool van die \\ Potchefstroomse Universiteit vir $\mathrm{CHO}$ \\ POTCHEFSTROOM
}

Om oor 'n onderwerp soos die taalgebruik by die bediening van die Woord van God te gesels is moeiliker as wat dit by die eerste ja-sê gelyk het. Moeiliker nog as jy so voortvarend is om voor te gee dat jy iets van godsdiensuitsending weet. Aan die ander kant: ek het gemeen dit gaan tog maar net oor kommunikasie, en oor die feit dat taal die duidelikste en die voor die hand liggendste manier van kommunikasie is. Dit is egter as ' $n$ mens jou gedagtes oor die onderwerp wil begin orden dat jy agterkom in watter wildernis jy jou bevind. Jy loop in die eerste plek die gevaar dat jy aardse uitsprake kan maak in aardse woorde oor 'n saak wat juis hoër as die aarde lê; jy loop die verdere gevaar dat jy as onopgeleide vir die teologies opgeleides wil kom sé hoe hulle iets moet kommunikeer wat veel, veel meer is as 'n blote stuk vakinhoud. Dus moet jy jouself die reg, en die wete, aanmatig dat jy weet hoe om dit wat jy self maar net op die geloof af hoop, aan ander te verduidelik. Dit gaan daarom nie net om kommunikasie nie, dit gaan juis om die soort kommunikasie wat groter is as woorde, dit gaan om die oopmaak van die diepste hinnekant van ons menswees hier op aarde. En dan uiteindelik om hierdie oopmaak oor 'n medium waar die gehoor onweetbaar groot en divers is.

Ek huiwer dus, want hoe kry jy jou diepste glo omgesit in woorde sodat jou woorde die hoorder se diepste dieptes kan omkeer; kan raak op so 'n manier dat jy in jouself daarvan oortuig is dat jy oorgedra het wat jy glo God van jou gevra het? As dit maklik was, sou u nie nou hier gesit het nie. Dit is 'n ander soort kommunikasie waarom dit gaan, juis omdat dit so gebiedend noodsaaklik is dat wat ' $n$ mens in jou prediking moet oordra. duidelik en verstaanbaar vir 'n hele spektrum van luisteraars oorgedra moet word.

Die vraag wat u tereg beantwoord sou wou hê moet dan juis wees: hoe dra jy dit oor sonder dat jou woorde oor hulle eie kommunikatiewe moontlikhede struikel?

Ek meen dat 'n mens logieserwys moet begin by die hele doel van kommunikasie, naamlik (natuurlik oorvereenvoudig gestel) dat dit wat jy as spreker in jou kop het

Oorspronklik aangebied by 'n seminaar oor mediahomiletick aangebicd deur die Depar-

tement Diakoniologic (PUCHO) in samewerking met die SAUK - Junic 1991. 
helder oorgeplant moet kom in die koppe van dié wat na jou luister. Tussen dit wat jy wil sê en dit wat jy gesê kry, moet so min as moontlik verskil wees. Dit wat jy dink jy sê moet ook dit wees wat jou hoorder dink jy wil sê; dit is die einddoel van kommunikasie: oordrag, deur middel van taal, met so min misverstand as moontlik. Daarom moet ' $n$ mens in die eerste plek duidelik wys op iets wat mense alte maklik as vanselfsprekend aanvaar, en dit is: sê wat jy wil sê, en sê dit met so min woorde as moontlik, want hoe meer woorde jy het, hoe groter is die moontlikhede vir foutiewe interpretasie. Daarmee bedoel ek nie dat herhaling verbode is nie. Ek bedoel as jy 'n feit, 'n waarheid, 'n sekerheid wil oordra, is dit kommunikatief wyser om dit met twee woorde oor te dra, al dink jy, en al dink jou nabymense dat dit mooier klink as jy sewe woorde vir dieselfde sê gebruik. 'n Mooi meisie word nie mooier as sy sewe byvoeglike naamwoorde mooier gesè word nie, sy word waarskynlik net al swaarder en al krommer van die las van jou woorddiarree. As die preek dan vyf minute korter is, maar dit sê vyf minute duideliker, laat dit dan liewer korter wees. Jou sê se slaankrag sit in sy vermoë om raak te slaan, nie om lank te slaan nie. Dit het u waarskynlik al oor en oor gehoor: oor die media moet jy jou luisteraar kan vashou met jou boodskap, want hy kan jou met die druk van 'n knoppie afskakel, of hy kan loop. As jy jou sê op jou papier gesê het, toets dan of jy dieselfde ding korter kan sê. Dit is een van die heel grootste geheime van die kreatiewe skryf: die wil om oor en oor te werk. Die selfdissipline om oor te skryf. Die gawe om nie moeg te word om moeg te word nie. Die radio en die televisie is een-kans-media: wat jy gesê het is klaar gesê, en as dit onverstaanbaar is, het jy jou kans gehad.

Verbale kommunikasie, dit wil sê dit wat woordeliks by ons monde uitloop, is maar ' $n$ baie klein deeltjie van kommunikasie. Kyk maar na iemand wat besig is om te praat. Hierdie klein deeltjie is al wat jy het as jy oor die radio moet praat. Alles wat jy wil oordra lê omtrent in woorde.

Die vermoë om sonder omhaal van onnodige woorde jou gedagtes oor te dra, gaan ook saam met jou vermoë om dit wat jy oor te dra het, in gewone woorde oor te dra. Ek weet dit klink veel deftiger en veel meer gewyd as die profete 'n rekommandasie prepareer in plaas daarvan dat hulle sommer ' $n$ aanbeveling voorberei; dit is seker so dat meer mense beindruk word deur 'n gigantiese pelu as deur 'n plein groot kussing, maar die vraag wat u moet beantwoord is ongelukkig (of dalk juis gelukkig!) nie hoe deftig dit klink nie, maar hoe verstaanbaar is dit? Dus: as u niks het om te sê nie, sê dit met groot woorde, maar as u iets het om te vertel, vertel dit dan in 'n Afrikaans wat vir $u$ hoorder toeganklik is. U preek immers nie om iemand met u woordeskat of u kreatiwiteit te beindruk nie, daarvoor is die boodskap waarom dit vir u gaan te groot, en die verstaanbaarheid daarvan te uiters belangrik. En: onthou dat u mediagemeente die heel hoogste en die heel laagste insluit. Dit is die ongewete gemeente, die een wat jy 
nie ken nie en die een wat jou nie beroep het nie. Jy sien hulle net die een keer, en jy kan jou woordpogings nie op hulle oefen nie, want hulle hoor net een keer.

Daar is wat my betref min dinge so skadelik vir goeie kommunikasie as swak taalgebruik. Slordige taalgebruik is soos slordige klere: dit dra 'n slordige ou daarbinne. As jy nie omgee hoe jy kommunikeer nie, kan jy nie verwag dat iemand gaan vermoed dat wat jy kommunikeer van belang moet wees nie. Ek praat dus eenvoudig van * oordrag in versorgde vorm. As die taal waarin jy kommunikeer keurig is, is 'n baie groot stuk van die oordrag reeds bewerkstellig. As die taalgebruik die indruk van versorging skep, dan moet jou hoorder mos al klaar daarvan oortuig wees dat jy iets te sê het. As jy nie eers die moeite doen om die medium te laat blink nie, hoe kan jy iemand daarvan oortuig dat die inhoud daarvan kan sprankel? Weer eens: jy hoef dit nie self alles te weet nie, maar daar is 'n horde toeganklike hulpmiddels. Jy hoef nie alles van taal af te weet nie, maar jy moet weet waar om te loop soek.

Alles wat tot dusver gesê is, klink miskien ook maar redelik boekerig, so al asof daar nie eintlik regtig 'n manier is om sinvol te kommunikeer nie; sinvol te preek nie, want alles lyk verkeerd sonder dat daar werklik aanbevelings is; sonder dat jy regtig jou standpunt stel. Ek meen dat 'n groot deel van die probleem ook gesoek moet word in ons stereotipe opvatting van wat Afrikaans nou eintlik is. Te lank, en die redes daarvoor is verduidelikbaar, het Afrikaans 'n soort elitistiese glans om hom rondgedra. Dit het verband gehou met die opvatting dat die sogenaamde Algemeen-Beskaafde vorm van 'n taal (enige taal) die enigste korrekte vorm van die taal is. Dit het duidelik die idee laat posvat dat die dialekte van 'n taal dan per definisie onbeskaafd moet wees. Dit geld nie net vir Afrikaans nie, maar vir die beskouing van taal oor die algemeen. Die dialekte van Nederlands was jare terug ook nie goed genoeg vir die preekstoel nie; gewone Engels was nie goed genoeg as taal van die Bybel nie. Hierdie opvatting oor taal het tot hier in die jare sestig nog redelik algemeen gegeld. Dialekte is gesien as verworwe vorme van 'n taal, en as sodanig is die dialekte as minderwaardig vir die oordra van die hoë kommunikasie gesien, in die besonder as onwaardig vir die uitdra van die Evangelie. Dit is byvoorbeeld een van die redes waarom die taal van die Afrikaanse kerk vir baie lank Hooghollands bly; dit is een van die redes hoekom die Afrikaanse Bybelvertaling eers agt jaar na die amptelike erkenning van Afrikaans volg. Maar selfs nadat Afrikaans Bybel- en kanseltaal word, bly dit streng die sogenaamde beskaafde vorm van Afrikaans. Die tradisie mak dan ook dat die Afrikaans van die Bybel en die Afrikaans van die kerk 'n onnatuurlike vorm van Afrikaans bly - onnatuurlik in die sin dat die taal waarin daar gepreek word hemelsbreed verskil van die een wat vir die gewone omgang gebruik word. Die gewone geselsafrikaans, die kaalvoet ene, die straathoektaal is vir lank beskou as die taal waarin jy nie die Here dien nie. 
Dit is natuurlik vir Afrikaans nog 'n entjie erger as vir die tale van Europa, sè nou maar Nederlands, want hier by ons het van die Afrikaanse dialekte ook nog ' $n$ kleurkonnotasie by, 'n konnotasie wat dit nog meer onaanvaarbaar maak as kanseltaal. Dit is selfs so dat iemand soos G.R. von Wielligh in die twintigerjare opmerk dat hy die taal van die Griekwas nie aan wetenskaplike ondersoek kan onderwerp nie, want verre sy dit van hom om hierdie veragterde vorm by sy bespreking te betrek. Hierdie opvat-

- ting oor 'aanvaarbare' Afrikaans loop natuurlik baie sterk in die Afrikaanse godsdiensoefening. Dit lei op sy beurt daartoe dat daar baie rigiede opvattings is oor watter vorm van Afrikaans aanvaarbaar is by die bediening van die Woord, veral die mediabediening. Reste van hierdie verouderde opvatting slaan myns insiens nog baie deur in die preekstyl van ons moderne predikante. Hiermee bepleit ek nie die platvloerse gebruik van Afrikaans oor die media nie! Ek bepleit eenvoudig maar die gebruik van gewone Afrikaans wanneer $u$ daarop uit is om die gewone luisteraar met $u$ preke te bereik; en die gewone luisteraar is nie die Algemeen-Beskaafde een nie. Kortom: praat met die hoorder in die taal van sy gewone omgang, die taal waarin hy met homself kommunikeer.

Doen moeite om die regte woorde te loop soek, maar wanneer u wil oordeel oor hierdie regte woord, is eenvoud vir my die antwoord, eenvoud in die sin van dié woord wat kommunikeer, die woord wat nie net by die ore ingaan nie, maar juis die woord wat kan deurdring tot die hart. Die boodskap wat u moet kommunikeer is so belangrik, so mooi en so sinvol dat u dit maar in gewone Afrikaans kan oorsê, juis omdat u die gewone hoorder van die verhewendheid van die boodskap wil oortuig. Moet dus nie gryp na die woordeboekwoord nie, vat juis die woord wat vanself hier langs u kom lê, want dit sal ook die woord wees wat naby aan die radio- en televisiegemeente se oor en sy hart lè.

U wil tog, hoop en glo ek, verstaan word; u moet tog God en sy boodskap van liefde en genade oordra, maar dit moet juis die boodskap vir alle mense wees, en alle mense is ouens soos ek wat van die teorie van die teologie nie veel verstaan nie, maar wat soek na die prakıyk van die Woord soos wat hy in die alledaagse lewe op alledaagse manier vergestalt word.

As ek dus u preek moes voorberei, sou ek die belangrikheid van die inhoud van die boodskap so hoog aanslaan dat ek dit sonder omhaal van woorde, veral die omhaal van groot woorde, in gewone Afrikaans wou uitsé juis omdat die boodskap wat ek het só belangrik is dat dit nie verlore mag gaan omdat ek iemand wil beindruk met die simbole van my boodskap nie, maar juis met die volle en volmaakte inhoud van dit wat ek oor die Here te vertelle het. Wat my betref: $u$ het so veel om te sea dat u dit asseblief gewoonweg moet sê sodat ons gewone mense dit juis moet kan verstaan. 